\title{
Sistema de dois níveis em Física da Oscilação de Neutrinos.
}

\section{Thiago M. Pradella*, Orlando L. G. Peres.}

\section{Resumo}

Neste trabalho foi tratado o mecanismo de oscilação de neutrinos através de uma interpretação geométrica, fazendo uma analogia com o modelo de precessão de Larmor. Esse modelo, que não é discutido de forma completa em nenhum livro de física de partículas e de mecânica quântica, permite tratar a oscilação de neutrinos como um exemplo de sistema de dois níveis, se tornando um tópico apropriado para se abordar em um curso de mecânica quântica.

\section{Palavras-chave:}

oscilação de neutrinos, Precessão de Larmor, mecânica quântica.

\section{Introdução}

Os neutrinos são as partículas de matéria mais abundantes do universo, apesar de serem uma das partículas menos compreendidas pelo conhecimento humano. O Modelo Padrão das Partículas Elementares é a teoria que descreve todas as partículas existentes e que não prevê massa nem oscilação para os neutrinos. No entanto, experimentos confirmaram a oscilação de neutrinos, na qual foi dado o Prêmio Nobel em 2015, e então foi provado que os neutrinos possuem massa, ainda que pequena. Esse impasse é o que torna a física de neutrinos tão relevante, e compreender a oscilação de neutrinos profundamente passa a ser importante. Desse modo, o objetivo desse trabalho foi compreender a oscilação de neutrinos no vácuo e na matéria de um modo geométrico usando como analogia a precessão de Larmor. A discussão feita nesse trabalho é pouco abordada na literatura, e serve para mostrar que esse modelo pode ser abordado em um curso de mecânica quântica como um exemplo de sistema de dois níveis.

\section{Resultados e Discussão}

Quando uma partícula de spin $1 / 2$ está em um campo magnético uniforme $\vec{B}_{0}$, seu operador spin $\vec{S}$ gira em torno de $\vec{B}_{0}$, e este fenômeno é chamado de Precessão de Larmor ${ }^{1}$. A equação que representa essa precessão é dada por:

$$
\frac{d \vec{S}}{d t}=\gamma \vec{S} \times \vec{B}_{0} .
$$

onde $\gamma$ é o fator giromagnético da partícula. Esse é o exemplo mais estudado em sistemas de dois níveis em mecânica quântica. Usando 0 formalismo matriz densidade ${ }^{1}$, foi obtido uma equação para a oscilação entre dois sabores de neutrinos $\left(v_{e}, v_{\mu}\right)$ no vácuo e na matéria análoga a equação da Precessão de Larmor:

$$
i \frac{d \rho(t)}{d t}=[H, \rho(t)] \Rightarrow \frac{d \vec{S}}{d t}=\vec{S} \times \vec{B}
$$

onde $\vec{S}$ e $\vec{B}$ são vetores em função das propriedades dos neutrinos, como ângulo de mistura $\theta$ e diferença dos quadrados das massas. Isso significa que podemos tratar a oscilação de neutrinos geometricamente ${ }^{2}$ do mesmo modo que a precessão de Larmor e como um sistema de dois níveis, como mostram as Figuras 1 e 2.
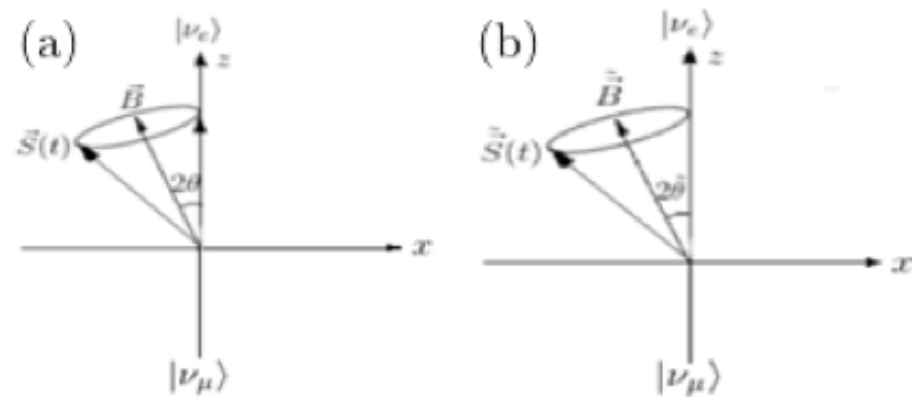

Figura 1. Representação geométrica da oscilação de neutrinos (a) no vácuo e (b) na matéria uniforme.
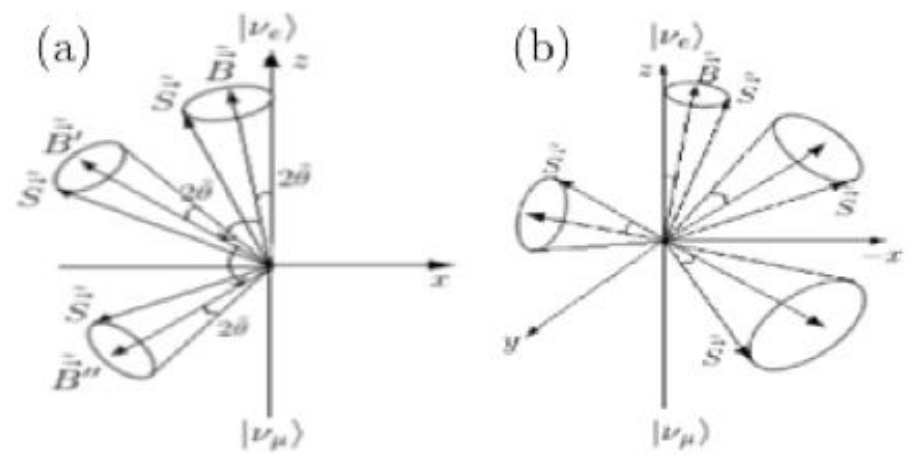

Figura 2. Representação geométrica da oscilação de neutrinos na matéria não uniforme (a) caso adiabático: quando a densidade de matéria varia lentamente com a posição, e o cone de precessão se desloca e (b) caso não adiabático: quando o cone de precessão se desloca e sua abertura varia.

\section{Conclusões}

Foi possível representar geometricamente a oscilação entre dois sabores de neutrinos, e assim, mostrar que ela pode ser tratada como um sistema de dois níveis análogo a uma partícula de spin $1 / 2$ em um campo magnético. Essa representação é importante para a compreensão aprofundada da oscilação de neutrinos bem como por ser mais um exemplo de sistemas de dois níveis.

\section{Agradecimentos}

Agradeço ao meu orientador pela paciência e orientação; e ao CNPq pelo suporte financeiro.

${ }^{1}$ Cohen-Tannoudji, C. Wiley-VCH. vol.1, 3.ed, 2005.

${ }^{2}$ Akhmedov, E. K. Nucl.Phys.Proc.Suppl. vol.221, pp.19-25, 2006. 